\title{
Overweight Increases the Risk of Right Ventricular Dysfunction in the Non-Breastfed Infants
}

\author{
${ }^{1}$ Nehad Taha Bishr, ${ }^{2}$ Mohamed S Darwish, ${ }^{3}$ Eman G. Amer, ${ }^{4}$ Azza M. Abul Fadl ${ }^{*}{ }^{5}$ Ayoub Al- \\ Jawaldeh \\ ${ }^{1,3}$ Lecturer of Pediatrics, Benha faculty of medicine, Egypt \\ ${ }^{2}$ Lecturer of Cardiology, Benha faculty of medicine, Egypt \\ ${ }^{4}$ Emeritus Professor of pediatrics, Benha faculty of medicine, Egypt \\ ${ }^{5}$ Lecturer in Nutrition sciences, University of Vienna, Austria
}

\begin{abstract}
Background: Overweight in infancy could increase the risk of cardiovascular disease (CVD) and diabetes mellitus (DM) in later life.

Aim: To assess the relationship between overweight and right ventricular function during infancy in relation to the mode of feeding.

Methods: A cross-sectional study was conducted for 76 healthy infants aged 3 to 12 months of life (38 breastfed (BF) and 38 milk formula fed (MFF). Anthropometric measurements were done for weight, supine length and body mass index (BMI). The right ventricular function (RVF) was assessed by two dimensional (2D) echocardiography and Tissue Doppler Imaging (TDI).

Results: BMI percentiles were significantly higher in MFF infants compared to BF infants $(\mathrm{P}<0.05)$. BMI was positively correlated with structural dimensions in MFF but not BF. BMI correlated with the echo parameters for M-mode, 2-D and TDI of RVF in BF but not MFF.

Conclusion: Overweight in MFF infants have an oversized right sided cardiac chamber, but breastfeeding promotes the functional development of the RV.
\end{abstract}

Keywords: Overweight, Echocardiography, Right Ventricle, Breastfeeding, Milk Formula Feeding, Right Ventricular Function.

\section{Introduction}

Childhood obesity is becoming an increasingly serious problem globally and in particular in the Eastern Mediterranean region (EMR) ${ }^{(1)}$. Worldwide 155 million (1 in 10) children are overweight and around 30-45 million classified as obese. Risk factors that predispose to develop obesity include hyperlipidemia, insulin resistance, diabetes mellitus (DM) and high blood pressure. High Body Mass Index (BMI) during childhood has been shown to be associated with adult obesity ${ }^{(2)}$. The World Health Organization (WHO) estimates that three quarters of deaths worldwide may be attributed to noncommunicable disease (NCD), of which cardiovascular disease (CVD) and DM tops the list ${ }^{(3)}$. Early feeding practices can influence the prevalence, morbidity and mortality from NCD as breastfeeding has a protective effect against obesity, hypertension, dyslipidemia and DM in adulthood ${ }^{(4)}$. However a review of studies linking early infant feeding practices with obesity has shown controversial findings ${ }^{(\mathbf{5})}$.

The cardiovascular system (CVS) has high growth and developmental rates in infancy and suboptimal diet during this period may permanently affect cardiovascular development ${ }^{(6)}$. So the patterns of nutritional exposures during infancy have an essential role in the cardiovascular development and associated CVD that may occur in adulthood ${ }^{(7)}$. Although overweight and obesity are a triggering factor for CVD yet early infant feeding practices maybe the underlying mechanism for protecting or perpetuating CVD and CVS complications of DM.

Retrospective follow-up of individuals who were low birth weight or with high rate of weight gain have increased risk of CVD ${ }^{(8)}$. Fetal growth restriction results in remodeled less efficient hearts in children ${ }^{(9)}$. 
This is suggests that fetal and child growth are linked to cardiovascular development and risk of later CVD. Decreased fetal growth was associated with adaptive fetal hemodynamic changes with increased cardiac overload and compromised arterial compliance ${ }^{(10)}$. Fetal growth restriction induces primary cardiac and vascular changes ${ }^{(11)}$.

The developmental plasticity hypothesis may lead to permanent adaptation in various organ systems with consequent short and long term risk to develop CVD. Overweight and obesity in the first two years of life were associated with larger hearts as shown by echo studies on the left side of the heart ${ }^{(12)}$. However there is minimal literature pertaining to overweight and obesity of cardiac dimensions on the right side of the heart.

The aim of this study is to identify echocardiography parameters and function of right chamber of the heart in overweight infants in relation to feeding practices in the first year of life.

\section{Methods}

Study design and population: This is a cross sectional case-control study that examined cardiac functions and dimensions in exclusively breastfed infants (EBF) with infants who were milk formula fed (MFF). This study was carried out for 74 infants aged from 3-12months, this was divided into two groups: Group (I): 36 EBF infants, Group (II): 38 MFF infants. Inclusion criteria were included healthy full term babies from birth until age of one year of both male and female babies and exclusively breastfeeding or formula feeding from birth. Exclusion criteria were included major congenital anomalies, acute or chronic diseases, babies on medications or exposed to irradiation and congenital heart disease. The children were selected from the outpatient clinic of Benha university Hospital.

The study was approved by Ethics Committee of Faculty of Benha University. Confidentiality was taken in consideration by using code number cod refer to name of the baby. Verbal informed consents were obtained from parents of all subjects of the study. General and systemic examination for heart and chest were done to exclude any abnormality. When using the reports and investigation of the baby we hide names and addresses and the results of investigation was done in the scientific publishing.

Anthropometry: Anthropometric measurements for weight to the nearest gram and expressed in kilogram. Supine length was measured to the nearest $\mathrm{mm}$ by standard methods ${ }^{(13)}$. Body mass index (BMI) was calculated by weight in $\mathrm{kg}$ divided by length squared in meters.

Echocardiography: Cardiac output (CO), heart rate (HR) and body surface area (BSA) were estimated by standard methods. Echocardiography measurements included right ventricular diameter (RVd mm), Right ventricular out tract diameter (RVOT mm), right ventricular velocity time integral (RV VTI/cm), Tricuspid annular plane excursion (TAPSE), Percent Fractional shortening (\%FS) or \%fractional area change (\%FAC) were measured using methods recommended by the American Society of Echocardiography. Right ventricular mass (RV mass) was computed using the formula derived by: (4/5 Pi D1D2L). Two-D, M-mode, continuous pulsed and color Doppler echocardiography were performed with standard sweeps including subcostal, parasternal, apical and suprasternal views ${ }^{(14)}$.

Statistical analysis: The collected data were tabulated and analyzed using SPSS version 16 software (SPSS Inc, Chicago, ILL Company). Categorical data were presented as number and percentages, Chi square $\left(\chi^{2}\right)$ and Fisher's exact test (FET) were used to analyze them. Quantitative data were tested for normality using Shapiro-Wilks test assuming normality at $\mathrm{P}>0.05$. Normally distributed variables were expressed as mean \pm standard deviation and analyzed by Student " $t$ " test for 2 independent groups. Correlations were estimated using Pearson's correlation coefficient. A P value $\leq 0.05$ was considered significant.

\section{Results}

Breastfed infants (BF) (36) were aged from 3 to 12 months with a mean of $7.6 \pm 3.08$ months, $16(44.4 \%)$ were under 6 months and 20 (55.6\%) were over 6 months of age, 14(38.9\%) were males and 22(61.1\%) were females. Milk formula fed infants (MFF) (38) were aged from 3 to 12 months with a mean of 7.5 \pm 2.9 months, $16(42.1 \%)$ were under 6 months and $22(57.9 \%)$ were over 6 months of age, 19(50.0\%) were males and $19(50.0 \%)$ were females There no significant difference between studied infants as regard age and sex (table 1). Mean maternal age was $27.1 \pm 4.3$ years for both groups. One third of the mothers in both BF and MFF groups were working (30.6\% and 36.8\% respectively) two thirds had some higher education $(77.8 \%$ and $78.9 \%$ respectively). Father's age was not different in both BF and MFF $(30.1 \pm 4.1$ and $29.8 \pm 3.8$ years 
respectively) and over one third were smokers (30.6\% vs. $42.1 \%$ ) with no significant differences between groups in studied variables $\mathrm{P}>0.05$ as shown in table (2).

Table (1): Distribution by age and sex of the studied population in relation to mode of feeding: breastfed vs. formula fed

\begin{tabular}{|c|c|c|c|c|c|c|c|}
\hline \multicolumn{2}{|c|}{ Variable } & \multirow{2}{*}{\multicolumn{2}{|c|}{$\begin{array}{l}\begin{array}{l}\text { Breast fed } \\
(\mathbf{n}=\mathbf{3 8})\end{array} \\
7.6 \pm 3.08\end{array}$}} & \multirow{2}{*}{\multicolumn{2}{|c|}{$\begin{array}{l}\text { Formula fed } \\
(\mathbf{n}=\mathbf{3 8})\end{array}$}} & \multirow{3}{*}{$\begin{array}{l}\begin{array}{l}\text { Test of } \\
\text { significance }\end{array} \\
\text { St.'t"= } \\
\text { 0.081 }\end{array}$} & \multirow{3}{*}{$\begin{array}{l}\text { P } \\
0.93 \text { (NS) }\end{array}$} \\
\hline \multirow{5}{*}{$\begin{array}{l}\text { Age } \\
(\mathrm{mo})\end{array}$} & Mean \pm SD & & & & & & \\
\hline & Range & \multicolumn{2}{|c|}{$3-12$} & \multicolumn{2}{|c|}{$3-12$} & & \\
\hline & & No. & $\%$ & No. & $\%$ & $\chi^{2}$ & $\mathbf{P}$ \\
\hline & $\leq 6 \mathrm{~m}$ & 16 & 44.4 & 16 & 42.1 & 0 & \\
\hline & $>6 \mathrm{~m}$ & 20 & 57.9 & 22 & 57.9 & 0.041 & 0.84 (INS) \\
\hline \multirow{2}{*}{ Sex } & Male & 14 & 38.9 & 19 & 50.0 & \multirow{2}{*}{0.92} & \multirow{2}{*}{0.33 (NS) } \\
\hline & Female & 22 & 61.1 & 19 & 50.0 & & \\
\hline
\end{tabular}

Mo: months, NS: not statistically significant, cut off value of significance is $\mathrm{P}<0.05$.

Table (2): Comparing the studied groups by socio-demographic characters of the parents

\begin{tabular}{|c|c|c|c|c|c|c|c|}
\hline \multicolumn{2}{|l|}{ Variable } & \multirow{2}{*}{\multicolumn{2}{|c|}{$\begin{array}{l}\begin{array}{l}\text { Breast fed } \\
(\mathbf{n}=\mathbf{3 8})\end{array} \\
27.1 \pm 4.3 \\
\end{array}$}} & \multirow{2}{*}{\multicolumn{2}{|c|}{$\begin{array}{l}\text { Formula fed } \\
(\mathbf{n}=\mathbf{3 8})\end{array}$}} & $\begin{array}{l}\text { Test of } \\
\text { significance }\end{array}$ & $\mathbf{P}$ \\
\hline \multirow{3}{*}{$\begin{array}{l}\text { Maternal } \\
\text { age (yrs) }\end{array}$} & Mean \pm SD & & & & & \multirow{2}{*}{0.18} & \multirow{2}{*}{0.86 (NS) } \\
\hline & \multirow[t]{2}{*}{ Range } & \multicolumn{2}{|c|}{$21-36$} & \multicolumn{2}{|c|}{$21-36$} & & \\
\hline & & No. & $\%$ & No. & $\%$ & $\chi^{2}$ & $\mathbf{P}$ \\
\hline \multirow{2}{*}{$\begin{array}{l}\text { Maternal } \\
\text { work }\end{array}$} & No & 25 & 69.4 & 24 & 63.2 & \multirow{2}{*}{0.33} & \multirow{2}{*}{$0.56(\mathrm{NS})$} \\
\hline & Yes & 11 & 30.6 & 14 & 36.8 & & \\
\hline \multirow{2}{*}{$\begin{array}{l}\text { Maternal } \\
\text { Education }\end{array}$} & Secondary & 8 & 22.2 & 8 & 21.1 & \multirow{2}{*}{0.015} & \multirow{2}{*}{0.90 (NS) } \\
\hline & High & 28 & 77.8 & 30 & 78.9 & & \\
\hline \multirow{2}{*}{$\begin{array}{l}\text { Father's age } \\
(\text { yrs })\end{array}$} & Mean \pm SD & \multicolumn{2}{|c|}{$30.1 \pm 4.1$} & \multicolumn{2}{|c|}{$29.8 \pm 3.8$} & \multirow{2}{*}{$\begin{array}{l}\text { T-test } \\
0.26 \\
\end{array}$} & \multirow{2}{*}{0.79 (NS) } \\
\hline & Range & \multicolumn{2}{|c|}{$24-40$} & \multicolumn{2}{|c|}{$24-40$} & & \\
\hline \multirow{2}{*}{$\begin{array}{l}\text { Father } \\
\text { smoker }\end{array}$} & No & 25 & 69.4 & 22 & 57.9 & \multirow{2}{*}{1.06} & \multirow{2}{*}{$0.30(\mathrm{NS})$} \\
\hline & Yes & 11 & 30.6 & 16 & 42.1 & & \\
\hline
\end{tabular}

The weight percentiles, weight/length (W/L) percentiles, BMI and BMI percentiles were significantly higher in formula fed infants compared to breastfed infants at $\mathrm{P}<0.05$. Over two thirds of the infants were introduced foods by six months (71.4\% in breastfed) and (62.1\% in MF) Table (3). 
Table (3): Comparing the studied groups regarding age of food introduction.

\begin{tabular}{|c|c|c|c|c|c|}
\hline \multirow{2}{*}{\multicolumn{3}{|c|}{$\begin{array}{l}\text { Age of food } \\
\text { introduction (months) }\end{array}$}} & \multicolumn{2}{|l|}{ Group } & \multirow{3}{*}{\begin{tabular}{|l} 
Total \\
17
\end{tabular}} \\
\hline & & & \multirow{2}{*}{$\begin{array}{l}\text { Breast fed } \\
6\end{array}$} & \multirow{2}{*}{\begin{tabular}{|l} 
Formula fed \\
11
\end{tabular}} & \\
\hline \multirow{4}{*}{ Age } & \multirow{2}{*}{5 months } & Count & & & \\
\hline & & $\%$ within Group & $28.6 \%$ & $37.9 \%$ & $34.0 \%$ \\
\hline & \multirow{2}{*}{6 months } & Count & 15 & 18 & 33 \\
\hline & & $\%$ within Group & $71.4 \%$ & $62.1 \%$ & $66.0 \%$ \\
\hline \multirow{2}{*}{\multicolumn{2}{|c|}{ Total }} & Count & 21 & 29 & 50 \\
\hline & & \% within Group & $100.0 \%$ & $100.0 \%$ & $100.0 \%$ \\
\hline
\end{tabular}

$$
\chi^{2}=0.47 \quad p=0.49 \text { (NS) }
$$

The echo structural dimensions and functions of the right side of the heart of BF male versus female breastfed infants are presented in Table (4). The echo structural dimensions and functions of the right side of the heart of MF male versus female non breastfed infants (artificially fed or MF fed) are presented according to sex in Table (5). There were no differences in the echo parameters in either age group.

Table (4): Echo parameters of the right side of the heart according to sex in the breastfed infants 3-12 months of age

\begin{tabular}{|c|c|c|c|c|c|c|c|}
\hline \multirow{2}{*}{\multicolumn{2}{|c|}{ Variable }} & \multicolumn{2}{|c|}{ Males $(n=19)$} & \multicolumn{2}{|c|}{ Females $(n=19)$} & \multirow{2}{*}{ T-test } & \multirow{2}{*}{ P-value } \\
\hline & & Mean & $\pm \mathrm{SD}$ & Mean & $\pm \mathrm{SD}$ & & \\
\hline \multicolumn{2}{|c|}{ RV Mass } & 5.38 & 0.58 & 4.74 & 1.40 & 1.92 & 0.06 \\
\hline \multicolumn{2}{|c|}{ FAC $\%$} & 52.06 & 5.46 & 50.18 & 4.71 & 1.06 & 0.29 \\
\hline \multicolumn{2}{|c|}{$\mathrm{E} \mathrm{cm} / \mathrm{s}$} & 80.76 & 10.62 & 80.20 & 11.05 & 0.15 & 0.88 \\
\hline \multicolumn{2}{|c|}{ E/A } & 1.31 & 0.13 & 1.31 & 0.20 & 0.103 & 0.92 \\
\hline \multicolumn{2}{|c|}{ TAPSE $\mathrm{cm}$} & 1.50 & 0.20 & 1.40 & 0.18 & 1.43 & 0.16 \\
\hline \multicolumn{2}{|c|}{ RVOTd cm } & 1.30 & 0.07 & 1.27 & 0.10 & 0.95 & 0.34 \\
\hline \multicolumn{2}{|c|}{ RV VTI cm/s } & 16.04 & 2.19 & 15.83 & 1.54 & 0.31 & 0.75 \\
\hline \multicolumn{2}{|c|}{ RV d cm } & 1.29 & 0.10 & 1.32 & 0.13 & 0.77 & 0.44 \\
\hline \multirow{6}{*}{ 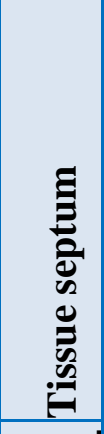 } & $S$ wave $\mathrm{cm} / \mathrm{s}$ & 7.82 & 0.83 & 8.03 & 1.07 & 0.66 & 0.51 \\
\hline & E wave cm/s & 11.30 & 1.26 & 11.26 & 1.21 & 0.079 & 0.93 \\
\hline & A wave $\mathrm{cm} / \mathrm{s}$ & 8.10 & 1.43 & 8.45 & 1.03 & 0.78 & 0.44 \\
\hline & ICT ms & 33.18 & 1.99 & 32.64 & 2.09 & 0.77 & 0.44 \\
\hline & IRT ms & 34.22 & 1.99 & 34.28 & 1.32 & 0.096 & 0.92 \\
\hline & E/e' & 7.19 & 0.89 & 7.04 & 0.52 & 0.56 & 0.57 \\
\hline 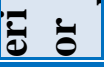 & $S$ wave $\mathrm{cm} / \mathrm{s}$ & 9.60 & 1.58 & 10.50 & 1.30 & 1.77 & 0.085 \\
\hline
\end{tabular}




\begin{tabular}{|l|l|l|l|l|l|l|}
\hline E wave cm/s & 13.62 & 1.83 & 14.24 & 1.84 & 0.98 & 0.33 \\
\hline A wave cm/s & 8.98 & 2.16 & 9.58 & 2.63 & 0.75 & 0.46 \\
\hline ICT ms & 33.27 & 1.60 & 33.00 & 2.11 & 0.44 & 0.66 \\
\hline IRT ms & 34.31 & 2.03 & 34.57 & 1.22 & 0.42 & 0.68 \\
\hline E/e' prime & 6.00 & 0.99 & 5.67 & 1.04 & 0.95 & 0.35 \\
\hline
\end{tabular}

RV: right ventricle; CO: Cardiac Output; RV-ESV: right ventricular end systolic volume; RV-EDV: right ventricular end diastolic volume; \%FAC: percent fractional area change; TAPSE: Tricuspid annular plane systolic excursion; RVOTd: right ventricular outflow tract diameter; right ventricular velocity time integral (RV VTI); E: rapid early (passive) RV filling; E/e': E wave to e prime ratio; ICT: isovolumetric contraction time, IRT: isovolumetric relaxation time;. $\mathrm{r}=$ Pearson correlation coefficient; *Significant $(\mathrm{P}<0.05)$.

Table (5): Echo parameters of right side of the heart according to sex in the Formula fed infants 3 to 12 months of age

\begin{tabular}{|c|c|c|c|c|c|c|c|}
\hline \multirow{2}{*}{\multicolumn{2}{|c|}{ Variable }} & \multicolumn{2}{|c|}{ Males $(n=19)$} & \multicolumn{2}{|c|}{ Females $(n=19)$} & \multirow{2}{*}{ T-test } & \multirow{2}{*}{$\mathbf{P}$} \\
\hline & & Mean & \pm SD & Mean & \pm SD & & \\
\hline \multicolumn{2}{|c|}{ RV Mass gms } & 5.24 & 0.68 & 5.06 & 0.74 & 0.79 & 0.43 \\
\hline \multicolumn{2}{|c|}{ FAC $\%$} & 52.06 & 5.46 & 50.18 & 4.71 & 1.06 & 0.29 \\
\hline \multicolumn{2}{|c|}{$\mathrm{E} \mathbf{c m} / \mathrm{s}$} & 80.76 & 10.62 & 80.20 & 11.05 & 0.15 & 0.88 \\
\hline \multicolumn{2}{|l|}{ E/A } & 1.31 & 0.13 & 1.31 & 0.20 & 0.103 & 0.92 \\
\hline \multicolumn{2}{|c|}{ TAPSE $\mathbf{c m}$} & 1.52 & 0.18 & 1.59 & 0.18 & 1.08 & 0.28 \\
\hline \multicolumn{2}{|c|}{ RVOTd cm } & 1.29 & 0.11 & 1.27 & 0.08 & 0.47 & 0.64 \\
\hline \multicolumn{2}{|c|}{ RV VTI cm } & 18.09 & 3.12 & 16.42 & 2.01 & 1.95 & 0.059 \\
\hline \multicolumn{2}{|c|}{ RV d cm } & 1.29 & 0.10 & 1.25 & 0.08 & 1.31 & 0.19 \\
\hline \multirow{6}{*}{ 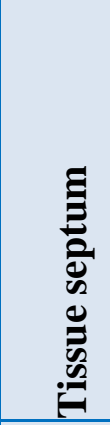 } & S wave $\mathrm{cm} / \mathrm{s}$ & 8.12 & 0.74 & 8.28 & 0.86 & 0.62 & 0.53 \\
\hline & E wave $\mathrm{cm} / \mathrm{s}$ & 11.69 & 1.35 & 11.91 & 1.04 & 0.56 & 0.58 \\
\hline & A wave $\mathrm{cm} / \mathrm{s}$ & 7.97 & 1.34 & 8.52 & 1.34 & 1.27 & 0.21 \\
\hline & ICT ms & 32.52 & 2.65 & 32.47 & 1.80 & 0.071 & 0.94 \\
\hline & IRT ms & 33.73 & 2.82 & 33.57 & 1.38 & 0.22 & 0.82 \\
\hline & $\mathbf{E} / \mathbf{e}^{\prime}$ & 7.19 & 0.89 & 7.04 & 0.52 & 0.56 & 0.57 \\
\hline \multirow{6}{*}{ 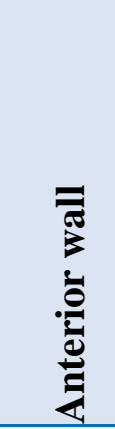 } & $S$ wave $\mathrm{cm} / \mathrm{s}$ & 10.44 & 1.71 & 10.92 & 1.20 & 1.01 & 0.32 \\
\hline & E wave $\mathrm{cm} / \mathrm{s}$ & 13.48 & 1.45 & 13.97 & 1.87 & 0.899 & 0.37 \\
\hline & A wave $\mathrm{cm} / \mathrm{s}$ & 9.39 & 2.03 & 9.93 & 2.54 & 0.72 & 0.47 \\
\hline & ICT ms & 32.73 & 1.52 & 32.94 & 1.71 & 0.40 & 0.69 \\
\hline & IRT ms & 34.47 & 1.50 & 34.00 & 1.63 & 0.93 & 0.36 \\
\hline & E/e' & 6.00 & 0.99 & 5.67 & 1.04 & 0.95 & 0.35 \\
\hline
\end{tabular}

RV: right ventricle; CO: Cardiac Output; RV-ESV: right ventricular end systolic volume; RV-EDV: right ventricular end diastolic volume; \%FAC: percent fractional area change; TAPSE: Tricuspid annular plane systolic excursion; RVOTd: right ventricular outflow tract diameter; right ventricular velocity time integral 
(RV VTI); E: rapid early (passive) RV filling; E/e': E wave to e prime ratio; ICT: isovolumetric contraction time, IRT: isovolumetric relaxation time;. $\mathrm{r}=$ Pearson correlation coefficient; *Significant $(\mathrm{P}<0.05)$.

Correlation between BMI and the echo parameters of the right side of the heart in both the BF and MF infants aged 3-12 months are presented in table (6). BMI was positively correlated with RV mass (gms) in MF (r0.4 at $\mathrm{P}=0.015$ ) but not in $\mathrm{BF}(\mathrm{r} 0.08$ at $\mathrm{P}>0.05$ ) and \%FAC in $\mathrm{MF}$ ( $\mathrm{r} 0.4$ at $\mathrm{P}=0.03$ ) but it was borderline and statistically insignificant in $\mathrm{BF}$ ( $\mathrm{r} 0.3$ at $\mathrm{P}=0.053)$. BMI was significantly positively correlated with RVOT diameter $(\mathrm{cm})$ in MF ( $\mathrm{r} 0.4$ at $\mathrm{P}=0.013)$ but not $\mathrm{BF}(\mathrm{r} 0.16$ at $\mathrm{P}>0.05)$. There was a significant positive correlation between RV VTI cm/s and BMI in only BF (r0.4 at $\mathrm{P}=0.03$ ) but not statistically significant in MF (r0.1 at $\mathrm{P}>0.5$ ). There was a significant positive correlation between ICT ms measured at anterior wall and $\mathrm{BMI}$ in only $\mathrm{BF}(\mathrm{r} 0.4$ at $\mathrm{P}=0.01)$ but not statistically significant in $\mathrm{MF}(\mathrm{r} 0.3$ at $\mathrm{P}>0.5)$. There were no significant correlations with other echo parameters as tricuspid signal as shown in table (7). Hence BMI in BF correlated only with functional echo parameters of the right heart, while BMI in MF correlated with structural parameters of the right side of the heart.

Table (6): Correlation between Body mass index and the Echo parameters in breastfed and Formula fed infants aged 3 to 12 months of age

\begin{tabular}{|c|c|c|c|c|c|}
\hline \multirow{2}{*}{\multicolumn{2}{|c|}{ BMI correlated with }} & \multicolumn{2}{|c|}{$\begin{array}{l}\text { In Breast fed } \\
(n=38)\end{array}$} & \multicolumn{2}{|c|}{$\begin{array}{l}\text { In Formula fed } \\
(n=38)\end{array}$} \\
\hline & & $\mathbf{r}$ & $\mathbf{P}$ & $\mathbf{r}$ & $\mathbf{P}$ \\
\hline \multicolumn{2}{|c|}{ RV Mass gms } & 0.08 & 0.61 & 0.393 & $0.015(\mathrm{~S})$ \\
\hline \multicolumn{2}{|c|}{ FAC $\%$} & 0.326 & 0.053 & 0.358 & $0.027(\mathrm{~S})$ \\
\hline \multicolumn{2}{|c|}{$\mathrm{E} \mathrm{cm} / \mathrm{s}$} & 0.064 & 0.71 & 0.306 & 0.062 \\
\hline \multicolumn{2}{|c|}{ E/A } & -0.115 & 0.50 & 0.184 & 0.26 \\
\hline \multicolumn{2}{|c|}{ TAPSE cm } & 0.238 & 0.16 & 0.232 & 0.16 \\
\hline \multicolumn{2}{|c|}{ RVOTd cm } & 0.157 & 0.36 & 0.401 & $0.013(\mathrm{~S})$ \\
\hline \multicolumn{2}{|c|}{ RV VTI cm/sec } & 0.357 & $0.032(\mathrm{~S})$ & 0.110 & 0.51 \\
\hline \multicolumn{2}{|c|}{ RV d cm } & 0.033 & 0.84 & 0.064 & 0.70 \\
\hline \multirow{6}{*}{ 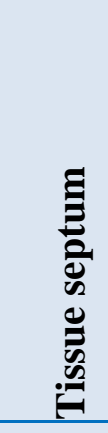 } & $S$ wave $\mathrm{cm} / \mathrm{s}$ & -0.085 & 00.62 & 0.043 & 0.799 \\
\hline & E wave $\mathrm{cm} / \mathrm{s}$ & 0.091 & 0.59 & -0.169 & 0.31 \\
\hline & A wave $\mathrm{cm} / \mathrm{s}$ & 0.161 & 0.35 & 0.332 & 0.042 \\
\hline & ICT ms & 0.320 & 0.057 & 0.189 & 0.25 \\
\hline & IRT ms & 0.135 & 0.43 & 0.155 & 0.35 \\
\hline & E/e' & 0.059 & 0.73 & 0.295 & 0.072 \\
\hline \multirow{6}{*}{ 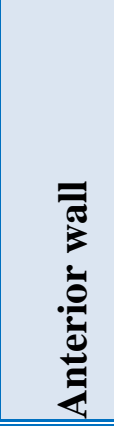 } & $S$ wave $\mathrm{cm} / \mathrm{s}$ & -0.128 & 0.45 & 0.024 & 0.88 \\
\hline & E wave $\mathrm{cm} / \mathrm{s}$ & 0.272 & 0.11 & 0.105 & 0.53 \\
\hline & A wave cm/s & 0.102 & 0.55 & -0.009 & 0.95 \\
\hline & ICT ms & 0.402 & $0.015(\mathrm{~S})$ & 0.306 & 0.062 \\
\hline & IRT ms & 0.108 & 0.53 & 0.224 & 0.17 \\
\hline & $\mathbf{E} / \mathbf{e}^{\prime}$ & -0.154 & 0.37 & 0.149 & 0.37 \\
\hline
\end{tabular}


BMI: Body mass index; RV mass: right ventricle mass; \%FAC: percent fractional area change; E: rapid early (passive) RV filling; TAPSE: Tricuspid annular plane systolic excursion; RVOTd: right ventricular outflow tract diameter; right ventricular velocity time integral (RV VTI); ICT: isovolumetric contraction time, IRT: isovolumetric relaxation time; E/e': E wave to e prime ratio;. $\mathrm{r}=$ Pearson correlation coefficient; *Significant $(\mathrm{P}<0.05)$.

\section{Discussion}

In this cross-sectional study of healthy infants in the first 12 months of life, we found that infants exposed to formula feeding tended were overweight and had higher BMIs than those who were breastfed, although mothers in both groups had similar ages and background education. A study suggested that the gain in weight among MFF infants and increase in their BMI was more in the first 3-6 months of life than infants who were EBF or predominantly breastfed infants and was due to a progressive increase in lean body mass (15). Another study including a total of 158 infants (72 exclusively breastfed and 86 exclusively formula-fed) reported that body composition was similar between the two groups at enrolment, but fat-free mass at 4 months and the fat-free mass changes between enrolment and 4 months were higher in formula-fed infants than breastfed ones ${ }^{(16)}$. In contradistinction, another study showed that EBF infants showed a significantly higher fat mass accretion ${ }^{(17)}$. Hence there is considerable controversy regarding fat mass accretion between breastfed and formula fed. The differences could be attributed to the feeding frequency or technique of feeding. However on the long term cardiovascular disease (CVD), risk factors and biomarkers that predict CVD were found higher in babies exposed to $\mathrm{MFF}^{\left({ }^{(18)}\right.}$.

Overweight and passive smoking were both higher in the formula fed which could explain the higher tendency not to breastfeed. However the difference in exposure was not significant. A systemic review from 42 articles (30 reviews and 12 observational studies) of the relationship between exposure in infancy to passive smoking and CVD has shown passive smoking may be implicated in deteriorating cardiovascular status (CVS) in children in terms of unfavourable high-density lipoprotein levels and deteriorated vascular function ${ }^{(19)}$. Tobacco smoke contains substances that can be toxic to the CVS arsenic and may be carcinogenic as dioxins and benzene ${ }^{(\mathbf{2 0}, \mathbf{2 1})}$. Moreover early childhood growth is affected by maternal smoking ${ }^{(22)}$, which could in turn influence cardiac parameters.

Early introduction of foods before 6 months of age can predispose to overweight and obesity. In our study about one third of all infants introduced foods before 6 months of age. However more MF fed infants were introduced foods earlier (38\%) compared to breastfed (28\%), this may explain the higher tendency of overweight in the former group. Other workers have shown that early weaning foods were associated with biomarkers of CVD with lower HDL, higher LDL and higher highly sensitive C-reactive protein in babies exposed to early weaning foods before 6 months of age ${ }^{(18)}$. Another study showed that early breastfeeding can lower cholesterol in later life by increasing body capacity to handle cholesterol ${ }^{(\mathbf{2 3}, \mathbf{2 4})}$ and prevent early rise in blood pressure ${ }^{(\mathbf{2 5})}$.

Structural and functional echo parameters of the right side of the heart did not differ between males to females. Although differences in cardiac structural and functional parameters exist between males and females exist in adults, these were not evident in early infancy. Other studies showed TAPSE values were positively correlated with increasing age and surface area, with no significant differences between sexes ${ }^{\text {(26) }}$. In another study body weight and weeks of gestation showed strong positive correlation with TAPSE values with no significant differences between sexes ${ }^{(27)}$. The European study on echocardiographic data of over 2,000 healthy children revealed no significant differences in echocardiographic values between the sexes were found ${ }^{(\mathbf{2 8})}$. Previous other studies have suggested differences in cardiovascular structures in relation to age, height, weight and BSA in adults but not in children in relation to the RV ${ }^{(29)}$. A study in Egypt that screened 200 girls aged 9-12 years by echocardiography showed that onset of puberty is accompanied by an increase in aortic dimensions to cope with hemodynamic changes in this critical period of body growth and development ${ }^{(30)}$. This probably indicates that preferential differences in cardiac structures related to sex may be influenced by hormonal factors rather than by genetic make-up ${ }^{(31)}$. The underlying mechanisms that link early feeding practices with development of CVD could be genetically determined as early exclusive breastfeeding was shown to influence the allelic polymorphism by altering susceptible and protective genes 
of the HLA system in Type 1 DM in children ${ }^{(32)}$. Moreover screening obese adolescents through TDI echo showed a strong correlation between obesity, TDI findings and Homo tests for prediction of DM ${ }^{(333)}$.

The study also illustrated that right sided parameters for ventricular mass, and RVOT were significantly correlated with BMI, but only in the MFF and not in the breastfed. This is probably indicates that the early introduction of cow's milk based formula increases the risk to overweight and its pathological sequel. Early introduction of foods or milks can potentially challenge the immature body systems and organs in their early development and probably predispose them to increased susceptibility to disease or disordered function of such organs or systems. Not only is the fat the source of such disruption, but probably the protein both because of their quantity and quality ${ }^{(34)}$. On the other hand lower protein was associated with lower weight in the first 2 years of life ${ }^{(35)}$. Moreover the predisposition to obesity with increased BMI early in infancy increases the risk to CVD ${ }^{(36)}$. De Jonge et al. ${ }^{(\mathbf{1 2})}$ have shown similar findings on the left side of the heart with obesity and overweight, indicating that obesity can affect both sides of the heart.

On the other hand breastfed infants showed significant correlations between BMI and functional parameters of the right side of the heart as the RV VTI and ICT. The VTI is as a function of ventricular length ${ }^{(37)}$. It is a measure of the extent of blood flow across the tricuspid valve. Because of the large orifice and unusual shape of the RV the VTI on the right side is usually less than that on the left side. The higher VTI and CO in breastfed may indicate higher and more consistent blood flow across the TV indicating higher flow of blood. It follows that higher blood flow ensure adequate oxygenation of blood through the lungs and subsequently to organs and tissues of the body. Hence the higher BMI in breastfed increased the cardiac functional parameters, while the higher BMI in MFF increased cardiac structural size. However both were correlated with the \%FAC i.e. BMI was positively associated with ejection of more blood to the lungs. In the breastfed it was through higher velocities and in the formula fed it was through increase cardiac size. The latter may have long term effects on heart function by the modeling effects of early development ${ }^{(5)}$. The developmental plasticity hypothesis proposes that environmental exposures acting at different stages of fetal and postnatal development lead to permanent adaptation in various organ systems. This early programming contributes to short and long term morbidities and mortalities related to CVD ${ }^{(\mathbf{1 0})}$.

Limitations: A potential limitation of the study is that the associations between overweight and right cardiac structures may depend on additional dietary patterns. In the analysis, we did not adjust for other components of infant diet. Another limitation was that because of the young age at examination and the limited time available at the visits, we were not able to get a higher percentage of successful cardiovascular measurements of the left side of the heart.

Conclusions: Results from this cross-sectional study suggest that overweight in infancy may influence risk of CVD ${ }^{(39,40)}$ by influencing RV function early on in infancy. This could have repercussions for CVD in adult life and the complications resulting from non-communicable diseases especially as in the case of DM (41)

Recommendations: To implement to guidelines for control of obesity suggested by the Eastern Mediterranean Regional office of the World Health Organization (WHO-EMRO) ${ }^{(1)}$ that include encouraging healthy diet from birth by promoting, protecting and supporting breastfeeding through the Baby-friendly Hospital Initiative and community initiatives for supporting exclusive breastfeeding in the first six months of life and continued breastfeeding for two years or more; and protecting breastfeeding by monitoring implementation of the International code of marketing breastmilk substitutes and the relevant subsequent resolutions ${ }^{(\mathbf{1})}$. In addition recommendations include healthy diets for older children, limiting fast foods, foods rich in trans-fatty acids, salt and sugars, encouraging exercise and promoting healthy life styles. Echocardiography should be one of the mainstay non-invasive technologies that can be used in monitor and early detection of high risk cases for CVD ${ }^{(42)}$.

\section{References:}

[1.] World Health Organization. Tackling obesity in the Eastern Mediterranean region. East Mediterr Health J. 2019;25(2):142-143.

[2.] Freedman DS et al. The relation of childhood BMI to adult adiposity: the Bogalusa Heart Study. Pediatrics, 2005; 155(1):22-27. 
[3.] Abul-Fadl AM, Al-Jawaldeh A. Infant feeding and cardiovascular disease: A multistaged analysis from global to country data. Int J Scientific Research and Management. 2019;7(04)154-163.

[4.] Keldishadi R., Farajian S. The protective effects of breastfeeding on chronic non-communicable diseases in adulthood: A review of evidence. Adv. Biomed. Res. 2014;3:3.

[5.] Ryan AS. Breastfeeding and the risk of childhood obesity. Coll Antropol. 2007;31:19-28.

[6.] Singhal A, Lucas A. Early origins of cardiovascular disease: is there a unifying hypothesis? Lancet. 2004; 363:1642-5.

[7.] Rudnicka AR, Owen CG, et al. The effect of breastfeeding on cardiorespiratory risk factors in adult life. Pediatrics. 2007; 119(5):e1107-e1115.

[8.] Jiang B., Godfrey K., Martyn CN., Gale CR. Birth weight and cardiac structure in children. Pediatrics. 2006, 117:e257-61.

[9.] Crispi F., Bijners B., Figueras F., Bartorons J., Elxarch E., Le Noble F., Ahmed A., Gratacos E. Fetal growth restriction results in remodelled less efficient hearts in children. Circulation. 2010; 121:2427-31.

[10.] Cohen G., Jeffery H., Lagercrantz H., Katz-Solamon M. Long-term programming of cardiovascular function in infants of active smokers. Hypertension. 2010; 55:722-8.

[11.] Geerts CC, Bots ML, vader-Ent CK., Grobbee DE, Uiterwaal CS. Parental smoking and vascular damage in their 5-year old children. Pediatrics. 2012; 129:45-54.

[12.] de Jonge LL, van Osch-Gevers L, et al. Growth, obesity, and cardiac structures in early childhood: the Generation R Study. Hypertension. 2011;57:934-40.

[13.] Abul-Fadl AM., Khashaba A, Sharkawy A. Introduction to human growth and development. Third edition; Tobgi Press; 2011,Cairo, Egypt.

[14.] Tissot C, Singh Y. et al. Echocardiographic evaluation of ventricular function for the neonatologist and pediatric intensivist. Front Pediatr.2018; 6:79.

[15.] Gridneva Z, Rea A, Hepworth AR et al. Relationship between breastfeeding patterns and maternal and infant body composition over the first 12 months of lactation. Nutrients. 2018;10(1):45.

[16.] Giannì ML, Roggero P, Morlacchi L, Garavaglia E, Piemontese P, Mosca F. Formula-fed infants have significantly higher fat-free mass content in their bodies than breastfed babies Acta Paediatr. 2014; Jul;103(7):e277-81.

[17.] Rodríguez-Cano AM, Mier-Cabrera J, Allegre-Dávalos AL, Muñoz-Manrique C, Perichart-Perera O. Higher fat mass and fat mass accretion during the first six months of life in exclusively breastfed infants. Pediatr Res. 2020; 87(3):588-594.

[18.] Behairy OA., Abul-Fadl AM, Arafa OS, Abuol-Fadl A, Attia MA. Influence of early feeding practices on biomarkers of cardiovascular disease risk in later life. Gazette of Egyptian Pediatric Association. 2017; 65:114-121.

[19.] Metsios GS., Flouris AD., Angioi M., Kouteddakis Y. Passive smoking and the development of cardiovascular disease in children: A systemic review. 2011; 2011:587650.

[20.] Rushton L. Health impact of environmental tobacco smoke in the home. Reviews on Environmental Health. 2004; 19(3-4):291-309.

[21.] Miller MD, Broadwin R, Green S, et al. Health effects assessment for environmental Tobacco smoke. Sacremento, Calif, USA: California Environmental Protection Agency; 2005.

[22.] Ong KK, Preece MA, et al. Size at birth and early childhood growth in relation to maternal smoking, parity and infant breastfeeding: longitudinal birth cohort study and analysis. Pediatr Res 2002;52(6): 8637.

[23.] Owen CG, Whincup PH, K, et al. Does initial breastfeeding lead to lower blood cholesterol in adult life? A quantitative review of the evidence. Am J Clin. Nutr. 2008; 88:305-14.

[24.] Martin RM, Ebrahim S, et al. Breastfeeding and atherosclerosis: intima-media thickness and plaques at 65-year follow-up of the Boyd Orr cohort. Arterioscler Thromb Vasc Biol. 2005; 25:1482-8.

[25.] Martin RM, Ness AR, et al. Does breastfeeding in infancy lower blood pressure in childhood? The Avon longitudinal study of parents and children (ALSPAC). Circulation. 2004; 109:1259-1266.

[26.] Uysal F, Bostan ÖM, et al, Determination of reference values for tricuspid annular plane systolic excursion in healthy Turkish children Anatol J Cardiol. 2016 May; 16(5): 354-359. 
[27.] Koestenberger M, Ravekes W, et al. Reference values of the right ventricular outflow tract systolic excursion in 711 healthy children and calculation of z-score values. Eur Heart J Cardiovasc Imaging. 2014 Sep; 15(9):980-6.

[28.] Kampmann C, Wiethoff CM, et al. Normal values of M mode echocardiographic measurements of more than 2000 healthy infants and children in central Europe. Heart. 2000;83:667-72.

[29.] Overbeek LI, Kapusta L,et al. New reference values for echocardiographic dimensions of healthy Dutch children. Eur J Echocardiogr. 2006;7:113-21.

[30.] Abul-Fadl AM., Agha H., Tawfik N., ElSayed M. Echocardiographic interpretation of cardiac function with puberty in girls. J Saudi Heart Assoc. 2015;27(4):3015-316.

[31.] Pettersen MD, Du W, et al. Regression equations for calculation of $\mathrm{z}$ scores of cardiac structures in a large cohort of healthy infants, children, and adolescents: an echocardiographic study. J Am Soc Echocardiogr. 2008;21:922-34.

[32.] Abul-Fadl AM., Idris A., Refaey D., Alhusseini NF., Ramsy H. Predictive and prognostic value of protective genes in Type I Diabetes Mellitus. MCFC-Egyptian Journal of Breastfeeding. 2012; 4:35-47.

[33.] Abul-Fadl AM, Husseiny NF., Assar EH., Bayoumi S., Dabour S. Assessment of cardiovascular risk in obese adolescents using Tissue Doppler studies in Egypt. Global Heart. 2018;13(4):389390.

[34.] Axelsson IE, Ivarsson SA, et al. Protein intake in early infancy: effects on plasma amino acid concentrations, insulin metabolism, and growth. Pediatr Res. 26:614-617.

[35.] Koletzko B, von Kries R, et al. Lower protein in infant formula is associated with lower weight up to age 2 y: a randomized clinical trial. Am J Clin Nutr. 89:1836-1845.

[36.] Maggio AB, Aggoun Y, et al. Associations among obesity, blood pressure, and left ventricular mass. J Pediatr. 2008; 152:489-93.

[37.] Solinski A, Klusmeier E. Centile Curves for Velocity Time Integral Times Heart Rate as a function of ventricular length: The use of minute distance is advantageous to enhance clinical reliability in children 2017. J Am Soc. Echo. 2018; 31(1):105-112e2.

[38.] Moreland J, Coombs J. Promoting and Supporting Breast-Feeding. Am Fam Physician. 2000 Apr 1; 61(7):2093-2100.

[39.] Martin RM, Ben Shlomo Y, et al. Breastfeeding and cardiovascular disease risk factors, incidence, and mortality: the Caerphilly study. J Epidemiol Community Health. 2005; 59(2): 121-9.

[40.] Martin RM, Davey Smith G, et al. Breastfeeding and cardiovascular mortality: the Boyd Orr cohort and a systematic review with meta-analysis. Eur Heart J. 2004; 25:778-86.

[41.] Hanseus, K., Bjorkhem, G., et al. Cardiac function in healthy infants and children: Doppler echocardiographic evaluation. Pediatr Cardiol. 1994; 15: 211-218. 